\title{
Casca de café em dietas para vacas em lactação: balanço de compostos nitrogenados e síntese de proteína microbiana ${ }^{1}$
}

\author{
Alexandre Lima de Souza ${ }^{2}$, Rasmo Garcia ${ }^{3}$, Rilene Ferreira Diniz Valadares ${ }^{4}$, Mara Lúcia \\ Albuquerque Pereira ${ }^{5}$, Luciano da Silva Cabral $^{6}$, Sebastião de Campos Valadares Filho ${ }^{3}$
}

\author{
1 Projeto financiado pela Fundação de Amparo à Pesquisa do Estado de Minas Gerais (FAPEMIG). \\ 2 Departamento de Ciências Biológicas/Zootecnia/UFMT. \\ 3 Departamento de Zootecnia/UFV. \\ ${ }^{4}$ Departamento de Medicina Veterinária/UFV. \\ ${ }^{5}$ Curso de Zootecnia - UESB - Pç. Primavera, 40 - Itapetinga, BA - 45700-000. \\ ${ }^{6}$ DZER/FAMEV/UFMT.
}

RESUMO - Avaliaram-se o balanço de compostos nitrogenados e a síntese de proteína microbiana (PBmic) de vacas alimentadas com dietas contendo diferentes níveis de casca de café $(0,0 ; 8,75 ; 17,5$ e 26,25\% da MS, correspondentes a 0,0 ; 3,5; 7,0 e 10,5\% de casca de café na MS total da dieta) em substituição ao milho na ração concentrada. Foram utilizadas 12 vacas da raça Holandesa com produção média de leite de 23,4 kg. A síntese de PBmic foi estimada utilizando-se os derivados de purinas na urina e no leite. Amostras de urina spot dos animais foram coletadas aproximadamente 4 horas após a alimentação da manhã. A análise de regressão não detectou efeito dos níveis de casca de café sobre o consumo de nitrogênio total (441,3 g.dia) e a excreção de $\mathrm{N}$ na urina (190,8 g/dia) e no leite $(114,7 \mathrm{~g} / \mathrm{dia})$. A casca de café aumentou a excreção de $\mathrm{N}$ nas fezes e promoveu balanço de $\mathrm{N}$ negativo. As excreções de alantoína na urina (294,6 mmol/dia), alantoína no leite (21,3 mmol/ dia), ácido úrico na urina $(42,3 \mathrm{mmol} / \mathrm{dia})$ e de derivados de purinas totais $(358,2 \mathrm{mmol} / \mathrm{dia})$ e a síntese de proteína microbiana (266,3 g/dia) não foram influenciadas pela adição de casca de café. Todavia, a casca de café não alterou a eficiência de síntese de PBmic, estimada em $136,8 \mathrm{~g}$ de $\mathrm{PBmic} / \mathrm{kg}$ de nutrientes digestíveis totais.

Palavras-chave: creatinina, derivados de purina, N-uréia, proteína microbiana, resíduo agroindustrial

\section{Coffee hulls in diet of lactating dairy cows: nitrogen balance and microbial protein synthesis}

\begin{abstract}
The effects of replacing ground corn with coffee hulls on $\mathrm{N}$ balance and microbial protein synthesis of lactating dairy cows were evaluated in this trial. Twelve crossbred Holstein-Zebu cows yielding on average $23.4 \mathrm{~kg} / \mathrm{day}$ of milk were used. The microbial protein synthesis was estimated by excretion of purine derivatives in urine and milk. Animas were fed diets containing the following coffee hulls levels (\% DM): 0.0, 3.5, 7.0 or 10.5\%. Spot urine samples were collected approximately 4 hours post-feeding. Regression analysis showed no effects of dietary coffee hulls levels on total nitrogen intake (441.3 g/day) and excretion of urine $\mathrm{N}$ (190.8 g/day) and milk N (114.7 g/day). However, feeding coffee hulls to lactating dairy cows increased fecal $\mathrm{N}$ excretion resulting in negative $\mathrm{N}$ balance. The increased dietary levels of coffee hulls did not affect excretions of milk allantoin $(294.6 \mathrm{mmol} /$ day), urinary allantoin $(21.3 \mathrm{mmol} /$ day $)$, uric acid $(42.3 \mathrm{mmol} / \mathrm{day})$, and purine derivatives $(358.2 \mathrm{mmol} /$ day). Microbial protein synthesis estimated by urinary excretion of purine derivatives averaged $266.3 \mathrm{~g}$ /day and did not differ across diets. In addition, efficiency of microbial protein synthesis averaged $136.8 \mathrm{~g}$ of microbial $\mathrm{N}$ per $\mathrm{kg} / \mathrm{TDN}$ and also did not differ among diets.
\end{abstract}

Key Words: agroindustrial residue, creatinine, microbial nitrogen, purine derivatives, urea $\mathrm{N}$

\section{Introdução}

As exigências protéicas dos ruminantes são satisfeitas, em grande parte, pela proteína microbiana digestível no intestino delgado e pela proteína não-degradável no rúmen, sendo a proteína microbiana a principal fonte de aminoácidos para estes animais. Desta forma, estimativas do balanço de compostos nitrogenados e da síntese de proteína microbiana obtidas para diferentes alimentos e dietas podem ajudar a explicar as diferenças observadas no desempenho animal.

A inclusão de alimentos concentrados na alimentação de animais ruminantes eleva a densidade energética e/ou protéica da dieta, favorecendo o consumo de nutrientes mais digestíveis, a síntese de proteína microbiana e, conseqüentemente, o desempenho animal. Entretanto, o elevado preço de ingredientes primários, como milho e farelo de 
soja, restringe a utilização destes produtos na alimentação de ruminantes e a manutenção de sistemas de produção mais intensivos.

A utilização de resíduos da agroindústria em substituição total ou parcial aos ingredientes concentrados consiste em alternativa econômica e ecologicamente promissora. Dependendo das características do material de origem e do tipo de processamento empregado, pode-se obter uma variedade de resíduos da agroindústria, alguns com diversas possibilidades de uso na alimentação de ruminantes.

A casca de café, resíduo proveniente do beneficiamento do grão pelo método de via seca (Caielli, 1984), por sua disponibilidade em diferentes países (Anuário Estatístico do Brasil, 2000) e por apresentar composição química favorável, pode representar mais um ingrediente a ser utilizado em programas de alimentação de ovinos e bovinos (Souza et al., 2004).

Este estudo foi realizado com o objetivo de avaliar o balanço de nitrogênio e a síntese de proteína microbiana em vacas consumindo dietas contendo diferentes níveis de casca de café em substituição ao milho da ração concentrada.

\section{Material e Métodos}

O experimento foi conduzido no Setor de Pesquisa e Ensino em Gado de Leite do Departamento de Zootecnia da Universidade Federal de Viçosa, no período de 01 de junho a 30 de julho de 2001. Foram utilizadas 12 vacas Holandesas (malhadas de preto, puras e mestiças) em lactação, com peso médio aproximado de $550 \mathrm{~kg}$ e produção média de leite de $23,4 \mathrm{~kg}$, distribuídas em três quadrados latinos 4 x 4, de acordo com o período de lactação. Cada período experimental teve duração de 15 dias, sendo os sete primeiros e adaptação e os oito dias finais destinados à coleta de amostras.

Os tratamentos foram constituídos de quatro níveis de casca de café $(0 ; 8,75 ; 17,5$ e $26,25 \%$ na MS $)$ em substituição ao fubá de milho da ração concentrada, correspondendo a $0 ; 3,5 ; 7,0$ e $10,5 \%$ de casca de café na MS total da dieta. As dietas (isoprotéicas, com aproximadamente $14,0 \%$ de PB) foram fornecidas ad libitum duas vezes ao dia, às $07 \mathrm{~h}$ e $16 \mathrm{~h} 30$, em quantidade suficiente para ocorrer de 5 a $10 \%$ de sobras. Os animais receberam quatro dietas completas contendo, na MS, $60 \%$ de silagem de milho e $40 \%$ de concentrado. A composição química do volumoso, da casca de café e das rações concentradas é apresentada na Tabela 1 .

Amostras de leite foram coletadas na $2^{\mathrm{a}}$ e $1^{\mathrm{a}}$ ordenhas do $12^{\circ}$ e $13^{\circ}$ dias, respectivamente, de cada período experimental, sendo misturadas proporcionalmente à produção de leite e analisadas quanto aos teores de PB, uréia e alantoína. As
Tabela 1 - Composição química da silagem de milho, da casca de café e das rações concentradas

Table 1 - Chemical composition of corn silage, coffee hulls and concentrate

\begin{tabular}{|c|c|c|c|c|c|c|}
\hline \multirow[t]{2}{*}{$\begin{array}{l}\text { Item } \\
\text { Item }\end{array}$} & \multirow{2}{*}{$\begin{array}{c}\text { Silagem } \\
\text { de milho } \\
\text { Corn } \\
\text { silage }\end{array}$} & \multirow{2}{*}{$\begin{array}{c}\text { Casca } \\
\text { de café } \\
\text { Coffe } \\
\text { hulls }\end{array}$} & \multicolumn{4}{|c|}{$\begin{array}{c}\text { Concentrado }{ }^{1} \\
\text { Concentrate }\end{array}$} \\
\hline & & & 0 & 8,75 & 17,5 & 26,25 \\
\hline MS $(D M) \%$ & 31,2 & 86,1 & 88,2 & 88,0 & 88,1 & 88,3 \\
\hline $\mathrm{MO}^{2}(O M)$ & 94,2 & 92,6 & 92,2 & 91,5 & 90,9 & 90,3 \\
\hline $\mathrm{PB}^{2}(C P)$ & 6,0 & 8,4 & 26,1 & 26,1 & 26,0 & 26,0 \\
\hline $\operatorname{NIDA}^{3}(A D I N)$ & 6,0 & 26,5 & 1,2 & 3,2 & 4,4 & 6,3 \\
\hline$E E^{2}$ & 2,8 & 1,0 & 3,3 & 3,0 & 2,7 & 2,4 \\
\hline $\mathrm{FDN}_{\mathrm{cp}}^{2}\left(N D F_{p}\right)$ & 50,9 & 53,6 & 10,5 & 14,6 & 18,0 & 22,2 \\
\hline $\mathrm{CNF}(N F C)$ & 34,5 & 29,6 & 52,3 & 47,8 & 44,2 & 39,7 \\
\hline $\mathrm{FDAi}^{2} \quad(A D F i)$ & 9,8 & 38,1 & 0,8 & 4,4 & 7,3 & 11,9 \\
\hline Lignina $^{2}$ (Lignin) & 3,3 & 14,7 & 1,0 & 2,8 & 4,3 & 6,3 \\
\hline $\operatorname{NDT}^{4}(T D N)$ & 64,15 & 44,07 & 80,95 & 75,85 & 71,73 & 66,79 \\
\hline $\begin{array}{l}\mathrm{EL}_{\mathrm{L}}{ }^{4} \mathrm{Mcal} / \mathrm{kg} \mathrm{MS} \\
N E_{L} \mathrm{Mcal} / \mathrm{kg} D M\end{array}$ & 1,44 & 0,85 & 2,13 & 1,98 & 1,86 & 1,71 \\
\hline
\end{tabular}

1 Porcentagem de casca de café no concentrado (com base na MS).

2 Valores em porcentagem da MS.

${ }^{3}$ Valores em porcentagem do nitrogênio total.

4 Estimado pelo NRC (2001).

1 Percentage of coffee hulls on concentrate, DM basis.

2 Values in DM basis.

${ }^{3}$ Values in percentage of total $N$.

${ }^{4}$ Estimated by NRC (2001)

$\mathrm{FDN}_{\mathrm{CP}}=\mathrm{FDN}$ livre de cinza e proteína ( $N D F_{a c p}=N D F$ without ash and protein); $\mathrm{CNF} \stackrel{\text { cp }}{=}$ carboidratos não-fibrosos $(N F C=$ nonfiber carbohydrates $) ; \mathrm{FDAl}=$ fibra em detergente ácido indigestível $(I A D F=$ indigestible acid detergent fiber): $\mathrm{EL}_{L}=$ energia líquida de lactação $\left(N E_{L}=\right.$ net energy lactation $)$.

amostras de fezes foram obtidas diretamente no reto dos animais, efetuando-se a coleta às $6,11 \mathrm{e} 15 \mathrm{~h}$ do $10^{\circ}, 12^{\circ}$ e $14^{\circ}$ dias, respectivamente, de cada período experimental.

A excreção fecal foi estimada utilizando-se a fibra em detergente ácido indigestível (FDAi) como indicador, conforme Cochran et al. (1986), com algumas alterações. As amostras de alimentos, sobras e fezes foram colocadas em sacos Ankon (Filter bags F57) e incubadas no rúmen de um animal por 144 horas. O material remanescente da incubação foi previamente lavado com água e submetido à extração com detergente ácido, cujo resíduo foi considerado FDAi.

A quantificação do volume urinário de cada animal, utilizado para o cálculo da excreção diária de nitrogênio total, uréia e derivados de purina (alantoína e ácido úrico) na urina foi feita multiplicando-se o valor da excreção média diária de creatinina $(29,00 \mathrm{mg} / \mathrm{kg} \mathrm{PV})$, obtida para vacas Holandesas em lactação (Valadares et al., 1999), pelo peso animal e dividindo-se o produto pela concentração de creatinina em $\mathrm{mg} / \mathrm{L}$, encontrada na amostra spot de urina dos respectivos animais. As amostras spot de urina de todos os animais foram coletadas no $13^{\circ}$ dia de cada período experimental, aproximadamente 4 horas após a alimentação da manhã. De cada amostra, retiraram-se $10 \mathrm{~mL}$ de urina, os quais foram diluídos em $40 \mathrm{~mL}$ de $\mathrm{H}_{2} \mathrm{SO}_{4}$ a $0,036 \mathrm{~N}$, a fim de 
se reduzir o $\mathrm{pH}$ para valores abaixo de 3 , evitando-se perdas de nitrogênio e destruição bacteriana dos derivados de purina. Em seguida, as soluções foram acondicionadas em potes plásticos e armazenadas em freezer para posteriores análises de uréia, creatinina, alantoína e ácido úrico.

As análises de alantoína foram realizadas pelo método colorimétrico, conforme descrito por Chen \& Gomes (1992). As análises de uréia, creatinina e ácido úrico foram feitas utilizando-se kits comerciais (Labtest). O cálculo das purinas microbianas absorvidas (PA, mmol/dia) foi feito a partir das excreções dos derivados de purinas ( $\hat{\mathrm{Y}}, \mathrm{mmol} / \mathrm{dia}$ ), utilizando-se a formula $\hat{\mathrm{Y}}=0,85 \mathrm{PA}+0,385 \mathrm{PV}^{0,75}$, em que 0,85 é a recuperação de purinas absorvidas como derivados urinários de purinas e $0,385 \mathrm{PV}^{0,75}$, a excreção endógena de purinas (Verbic et al., 1990). A excreção total de derivados de purina foi estimada pela soma das quantidades de ácido úrico e alantoína excretados na urina mais a quantidade de alantoína excretada no leite. Em razão da alta atividade de xantina oxidase nos tecidos e no sangue, grande parte da xantina e hipoxantina absorvida no intestino dos bovinos é convertida para ácido úrico, que, junto com a alantoína excretada na urina e no leite, representa a principal forma de excreção de derivados de purina (Chen \& Gomes, 1992).

A produção de proteína microbiana (PBmic) foi determinada a partir das purinas absorvidas (PA, mmol/dia), utilizando-se uma modificação da equação descrita por Chen \& Gomes (1992), na qual substituiu-se a relação Npurina:Ntotal nas bactérias de 0,116 para 0,117 , conforme relatado por Rennó et al. (2000): $\mathrm{Nmic}=(70 \mathrm{PA}) /(0,83 \times 0,117$ $\mathrm{x} 1000)$, em que 70 é o conteúdo de $\mathrm{N}$ de purinas ( $\mathrm{mgN} / \mathrm{mmol})$ e 0,83 , a digestibilidade das purinas microbianas.

Os teores de MO, nitrogênio total, FDN, EE, LIG e NIDA foram estimados segundo procedimentos descritos por Silva \& Queiroz (2002). Para cálculo do valor de energia líquida para lactação, estimado pelo NRC (2001), adotou-se o valor de NDT médio $(65,9 \%)$ observado para as quatro dietas experimentais.

Os resultados foram submetidos às análises de variância e de regressão, a 5\% de significância, por meio do Programa SAEG, versão 7.1 (UFV, 1997). A escolha do melhor modelo foi feita com base no coeficiente de determinação e na significância dos coeficientes de regressão, aplicando-se o teste " $t$ " de Student a 5\% de probabilidade.

\section{Resultados e Discussão}

Os consumos médios diários de MS de casca de café foram, respectivamente, de 0,$0 ; 645 ; 1.273$ e $1.963 \mathrm{~g}$ para os animais alimentados com as rações concentradas contendo 0,$0 ; 8,75 ; 17,5 ; \mathrm{e} 26,25 \%$ desse subproduto, correspondendo aos níveis de 0,$0 ; 3,5 ; 7,0 ;$ e 10,5\% de casca de café na MS da dieta. Os valores médios diários relativos ao consumo de nitrogênio total (NT), à excreção de compostos nitrogenados nas fezes (N-fecal), na urina (N-urina) e no leite (N-leite), ao balanço de nitrogênio e ao nitrogênio uréico no plasma (NUP), expressos de diferentes formas, com suas equações de regressão, são mostrados na Tabela 2. A análise de regressão não detectou efeito do consumo de NT e da excreção de N-urina e N-leite, expressos em g/dia, observando-se valores médios de 441,3; 190,8 e 114,7 g/dia, respectivamente. Todavia, verificou-se comportamento linear $(\mathrm{P}<0,05)$ para a excreção de $\mathrm{N}$-fecal e o balanço de $\mathrm{N}$, estimando-se, respectivamente, acréscimo de 1,245 e redução de 1,793 g/unidade de casca de café adicionada.

As elevadas concentrações de $\mathrm{N}$ na fração fibrosa da casca de café, em forma de NIDN e NIDA, considerados de baixa disponibilidade para os microrganismos do rúmen (Licitra et al., 1996), podem ter sido responsáveis pela maior excreção de $\mathrm{N}$-fecal e, conseqüentemente, pelo balanço negativo de $\mathrm{N}$.

Verificou-se, pela equação de regressão (Tabela 2), que o balanço de $\mathrm{N}$ atingiu valores negativos quando os níveis de casca de café no concentrado foram superiores a $11,06 \%$. Quando a casca foi incluída na ração concentrada em até $11,06 \%$, houve balanceamento adequado entre proteína e energia das dietas, suprindo as exigências dos animais; a partir deste nível, o balanço de $\mathrm{N}$ negativo pode ter sido favorecido pela menor digestibilidade da $\mathrm{PB}$ e pela diminuição da concentração de energia disponível da dieta.

Para a dieta sem casca de café, verificou-se que, do total de $\mathrm{N}$ consumido, aproximadamente $28,4 \%$ foi excretado como $\mathrm{N}$-fecal, $41,7 \%$ como $\mathrm{N}$-urina, 24,9 como $\mathrm{N}$-leite e $4,9 \%$ foi retido pelo animal. Na dieta com $26 \%$ de casca, no entanto, $36,4 \%$ do $\mathrm{N}$ consumido foi excretado como $\mathrm{N}$-fecal, $44,4 \%$ como N-urina, $26,1 \%$ como N-leite e $6,9 \%$ foi mobilizado do animal. Em estudos com vacas Holandesas e Jersey, Kauffman \& St-Pierre (2001) verificaram que, do total de N consumido (460 g/dia, aproximadamente), 40,3\% foi excretado como $\mathrm{N}$-fecal, $22,4 \%$ como $\mathrm{N}$-urina e $30,9 \%$ como $\mathrm{N}$-leite, enquanto $6,4 \%$ foi retido pelos animais alimentados com dietas com $13 \%$ de $\mathrm{PB}$ e $40 \%$ de fibra. A mobilização de $\mathrm{N}$ pelo animal pode resultar em perda de peso, além de afetar negativamente a reprodução dos animais, ressaltando-se que a intensidade dos efeitos é mais pronunciada na fase inicial da lactação, quando os animais de maior potencial produtivo estão normalmente predispostos a um quadro de balanço energético negativo (Head \& Gulay, 2000).

Os valores de N-uréia na urina (NU-urina), expressos em $\mathrm{g} / \mathrm{dia}$ e $\mathrm{mg} / \mathrm{kg} \mathrm{PV}$, não foram alterados $(\mathrm{P}>0,05)$ pelos níveis de casca de café nas dietas, registrando-se médias de 
Tabela 2 - Médias para consumo de nitrogênio total (NT), excreção de nitrogênio nas fezes (N-fecal), na urina (N-urina) e no leite (N-leite), balanço de $\mathrm{N}(\mathrm{BN})$, excreção de N-uréia na urina (NU-urina), no leite (NUL) e no plasma (NUP) e relação NUL/NUP, de acordo com os níveis de casca de café na ração concentrada (com base na MS), no coeficiente de variação (CV) e nas equações de regressão.

Table 2 - Effects of increasing dietary levels of coffee hulls on mean intake of total nitrogen (TN), excretions of nitrogen on feces (fecal $N$ ), urine (urinary $N$ ), and milk (milk N), excretion of urea nitrogen in urine (urinary UN), milk (milk UN), and plasma (plasma UN), nitrogen balance ( $N$ balance), and milk UN/plasma UN ratio

\begin{tabular}{|c|c|c|c|c|c|c|}
\hline \multirow[t]{2}{*}{ Item } & \multicolumn{4}{|c|}{$\begin{array}{c}\text { Dieta } \\
\text { Diet }\end{array}$} & \multirow[t]{2}{*}{ CV $(\%)$} & \multirow[t]{2}{*}{$\begin{array}{l}\text { Equações de regressão } \\
\text { Regression equations }\end{array}$} \\
\hline & 0,0 & 8,75 & 17,5 & 26,25 & & \\
\hline $\mathrm{N}$-fecal, g/dia (Fecal $N$, g/day) & 127,8 & 131,8 & 135,5 & 162,7 & 8,5 & $\hat{\mathrm{Y}}=123,14+1,245 \mathrm{X}\left(\mathrm{r}^{2}=0,78\right)$ \\
\hline N-urina, g/dia (Urinary $N, g /$ day) & 188,0 & 191,4 & 185,6 & 198,1 & 8,7 & $\hat{\mathrm{Y}}=190,8$ \\
\hline NU-urina, $\mathrm{mg} / \mathrm{kg} \mathrm{PV}$ (Urinary $U N, \mathrm{mg} / \mathrm{kg} B W$ ) & 272,7 & 283,0 & 278,3 & 292,4 & 9,0 & $\hat{\mathrm{Y}}=281,6$ \\
\hline NU-urina, g/dia (Urinary UN, g/day) & 152,0 & 158,5 & 157,0 & 162,6 & 9,7 & $\hat{\mathrm{Y}}=157,5$ \\
\hline NUL, g/dia (Milk UN, g/day) & 3,16 & 3,38 & 3,19 & 3,59 & & $\hat{\mathrm{Y}}=3,33$ \\
\hline NUL, mg/dL (Milk UN) & 13,72 & 14,27 & 13,98 & 14,84 & 10,9 & $\hat{\mathrm{Y}}=13,74+0,035 \mathrm{X}\left(\mathrm{r}^{2}=0,68\right)$ \\
\hline NUP $(P U N), \mathrm{mg} / \mathrm{dL}$ & 16,57 & 16,30 & 16,76 & 17,22 & 7,3 & $\hat{\mathrm{Y}}=16,7$ \\
\hline
\end{tabular}

$157,5 \mathrm{~g} / \mathrm{dia}$ e $281,6 \mathrm{mg} / \mathrm{kg} \mathrm{PV}$, respectivamente. As quantidades excretadas de NU-urina em g/dia representaram, respectivamente, 80,$8 ; 82,8 ; 84,6$ e $82,1 \%$ das excreções diárias de N-urina, para as dietas com $0 ; 8,75 ; 17,5$ e 26,25\% de casca na ração concentrada. Os valores de excreções de NU-urina foram muito inferiores aos observados por Valadares et al. (1999) que registraram valores de 239 a $342 \mathrm{~g} /$ dia para dietas com diferentes níveis de carboidratos não-fibrosos. Todavia, os valores observados neste experimento para excreção de U-urina, expressos em mg/kg PV, foram superiores aos valores de 330,1; 253,6; 434, 5 e 442,5 verificados por Silva et al. (2001), que utilizaram vacas lactantes recebendo dietas com $60 \%$ de silagem de milho e $40 \%$ de concentrado suplementadas com diferentes níveis de nitrogênio não-protéico.

O NUL (g/dia) e NUP (mg/dL) não foram influenciados $(\mathrm{P}>0,05)$ pelos níveis de casca de café nas dietas, apresentando valores médios de 3,33 g/dia e $16,70 \mathrm{mg} / \mathrm{dL}$, respectivamente. Todavia, a análise de regressão indicou efeito linear $(\mathrm{P}<0,05)$ dos níveis de casca sobre a concentração de NUL (em mg/dL), estimando-se aumento de 0,035. Comportamento semelhante foi reportado por Oliveira et al. (2001), que, embora não tenha detectado diferença nos valores de NU-leite expressos em g/dia, registraram comportamento linear crescente para os valores de NU-leite expressos em $\mathrm{mg} / \mathrm{dL}$ com a inclusão de níveis crescentes de compostos nitrogenados não-protéicos (NNP) nas dietas. Os valores médios observados de NU-leite e, conseqüentemente, seus correspondentes na forma de U-leite foram inferiores aos valores de 4,48; 4,93; 5,19 e 4,82 g/dia de NUL e de 22,09; 24,89; 27,34 e 27,46 mg/dL NUL relatados por Oliveira et al. (2001) para os animais que receberam dietas com 2,22; 4,18; 5,96 e $8,09 \%$ de NNP, respectivamente.

Os valores de NUP foram muito semelhantes ao de $16,43 \mathrm{mg} / \mathrm{dL}$ registrado por esses autores para as dietas com $2,22 \%$ de NNP. Diferentemente dos resultados encontrados por Oliveira et al. (2001) e McCormick et al. (2001) e de forma similar ao comportamento registrado por Kauffman \& St-Pierre (2001), a concentração de NUL para todas as dietas foi menor que a de NUP, registrando-se relação média de 85,9\%. Segundo Kauffman \& St-Pierre (2001), esse comportamento é justificado quando a taxa de difusão de uréia do sangue para a glândula mamária é menor que a de secreção de água das células epiteliais para os alvéolos da glândula mamária. Esses autores, ao citarem Guyton em 1982, relataram que a uréia é uma molécula maior e sua difusão é $20 \%$ mais lenta que a da água.

Tentativas têm sido feitas no intuito de se utilizar a concentração de NUL como ferramenta de manejo que auxilie no monitoramento do estado nutricional de vacas leiteiras. Nesse sentido, modelos matemáticos têm sido construídos para a estimativa da excreção de NU-urina e o estabelecimento das concentrações de NUL padrões para identificação das condições de manejo nutricional adequadas (Jonker et al., 1998; Jonker et al., 1999; Kauffman \& St-Pierre, 2001; Kohn et al., 2002). Jonker et al. (1999) afirmam que a concentração de NUL deve variar de 10 a $16 \mathrm{mg} / \mathrm{dL}$, dependendo do nível de produção, e que valores 
acima do máximo podem ser indicativo de consumo de $\mathrm{N}$ em excesso ou de excesso de proteína degradável no rúmen. Outros pesquisadores tentaram relacionar as concentrações de NUL aos índices reprodutivos dos animais. Assim, Rajala-Schultz et al. (2001), em experimentos com vacas provenientes de rebanhos de baixa ( $6850 \mathrm{~kg} / \mathrm{lactação)} \mathrm{e} \mathrm{de}$ alta produção (10916 kg/lactação), verificaram que níveis de NUL superiores a 15,4 mg/dL foram associados à menor eficiência reprodutiva. Todavia, Larson et al. (1997) relataram que somente as concentrações de NUL superiores a $21 \mathrm{mg} / \mathrm{dL}$ foram relacionadas a menores taxas de gestação. Considerando-se essas proposições, pode-se inferir que os valores de NUL obtidos com as dietas utilizadas neste experimento foram próximos aos padrões normais.

As excreções médias de alantoína, ácido úrico, purinas totais e purinas absorvidas e a síntese de PBmic para as diferentes dietas utilizadas são descritas na Tabela 3. A análise de variância não detectou efeito $(\mathrm{P}>0,05)$ dos níveis de casca de café sobre os derivados de purinas e a síntese de PBmic. As excreções médias urinárias de alantoína, de 285,7 a $310,8 \mathrm{mmol} / \mathrm{dia}$, foram superiores ao valor máximo de $258,1 \mathrm{mmol} / \mathrm{dia}$, estimado com amostras spot de urina, e próximos ao valor máximo de $297,1 \mathrm{mmol} / \mathrm{dia}$, calculado por Oliveira et al. (2001) pelo método de coleta de urina durante 24 horas, em experimentos com vacas (produção média de leite de $20 \mathrm{~kg} / \mathrm{dia}$ ) alimentadas com dietas isoprotéicas contendo diferentes níveis de uréia. Todavia, esses valores foram inferiores aos reportados por Valadares et al. (1999), de 369 a $535 \mathrm{mmol} /$ dia, para vacas com produção média diária de $40 \mathrm{~kg}$ de leite alimentadas com silagem de alfafa e diferentes níveis de concentrado. A relação alantoína excretada na urina $x$ total de derivados de purinas variou de 81,7 a $83 \%$ para as diferentes dietas (Tabela, 3), estando próxima aos valores de 85,4 e $87,8 \%$ encontrados por Oliveira et al. (2001).
A secreção média de alantoína no leite $(21,3 \mathrm{mmol} / \mathrm{dia})$ registrada neste experimento foi superior aos valores de 11,9 e 13,5 mmol/dia encontrados por Oliveira et al. (2001) e Silva et al. (2001), respectivamente. Foi próxima, no entanto, ao valor de $22,7 \mathrm{mmol} /$ dia verificado por Valadares et al. (1999) em animais recebendo dietas com $35 \%$ de concentrado. A produção de leite é um dos principais fatores a determinar a concentração e a quantidade de alantoína excretada no leite (Gonda \& Lindberg, 1997). A quantidade de alantoína excretada no leite variou de 5,7 a 6,2\% em relação à excreção total de derivados de purinas, sendo próxima à média de 5,7\% registrada por Valadares et al. (1999).

As excreções urinárias de ácido úrico (Tabela 3 ) foram superiores aos valores médios de 29,1 e $24,2 \mathrm{mmol} / \mathrm{dia}$ registrados por Silva et al. (2001) e está nas faixas descritas por Valadares et al. (1999), de 35,5 a 52,4 mmol/dia (obtida por coleta total de urina) e de 24,6 a 52,6 mmol/dia (amostras de urina spot). A excreção de ácido úrico representou, respectivamente, 12,$4 ; 11,9 ; 12,9$ e 12,8\% da excreção de derivados de purina na urina para as dietas com 0, 8,75; 17,5 e 26,25\% de casca de café na ração concentrada. Silva et al. (2001) registraram valores médios de $10,8 \%$, enquanto Johnson et al. (1998) encontraram valores de 12 a $45 \%$ e relataram que a relação ácido úrico e derivados de purinas na urina pode variar de acordo com a dieta e o estado fisiológico do animal.

A produção média de $\mathrm{N}$-microbiano de $266,3 \mathrm{~g}$ /dia registrada neste experimento foi superior aos valores máximos de 198,0 e 289,5 g Nmic/dia (amostras de urina spot) e 196,9 e 219,7 (coleta total de urina) reportados por Oliveira et al. (2001) e Silva et al. (2001), respectivamente. A eficiência de síntese de Pbmic (Emic) não foi alterada $(\mathrm{P}>0,05)$ pela adição de casca de café na ração concentrada, observando-se valores próximos à média de $130 \mathrm{~g}$ Pbmic/kg NDT adotada pelo NRC (2001).

Tabela 3 - Médias para excreções de alantoína na urina (ALU) e no leite (ALL), para ácido úrico na urina (ACU), purinas totais (PT), purinas absorvidas (PA), nitrogênio microbiano (Nmic) e eficiência microbiana (Emic), de acordo com os níveis de casca de café na ração concentrada (com base na MS), coeficiente de variação (CV) e equações de regressão

Table 3 - Effects of increasing dietary levels of coffee hulls on mean excretions of allantoin in urine (ALU), milk (ALM), urinary excretion of uric acid (ACU), total purine (TP), microbial N (CPmic) and microbial efficiency (Emic)

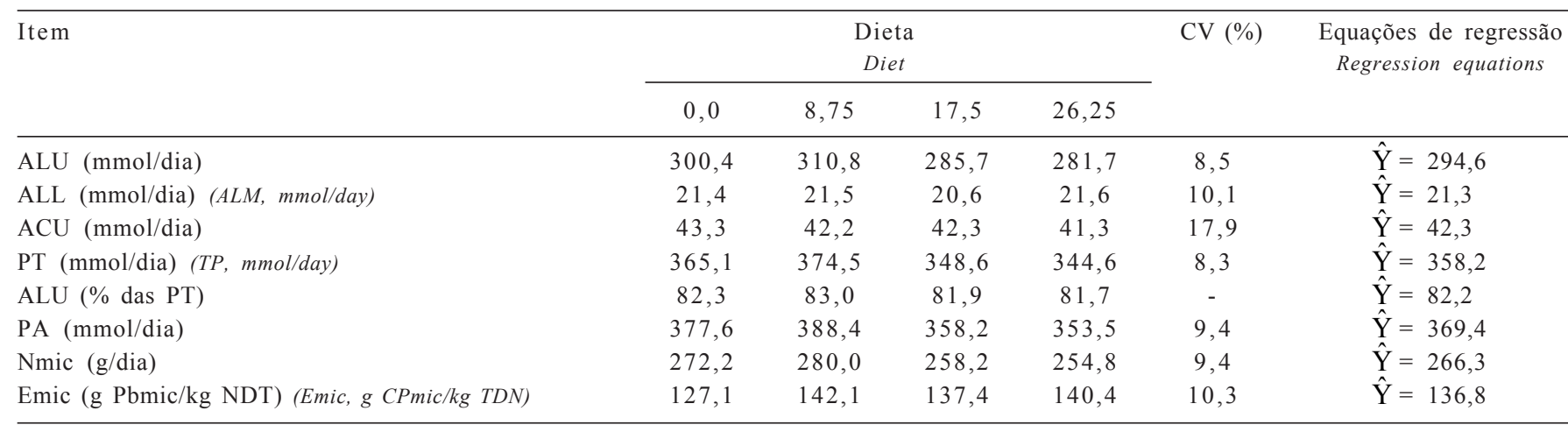




\section{Conclusões}

A inclusão de casca de café em níveis acima de $11 \%$ na matéria seca do concentrado ocasionou balanço de $\mathrm{N}$ negativo nos animais. Todavia, quando adicionada em até $26,25 \%$ no concentrado ( $10,5 \%$ da MS da dieta), a casca de café não alterou a produção e a eficiência de síntese de proteína microbiana, observando-se valores próximos à média de $130 \mathrm{~g}$ de Pbmic/kg de NDT recomendada pelo NRC (2001).

\section{Literatura Citada}

ANUÁRIO ESTATÍSTICO DO BRASIL. Aspectos das atividades agropecuária e da extração vegetal, v.60, seção 3, p.1-46, Rio de Janeiro, 2000.

CAIELLI, E.L. Uso da palha de café na alimentação de ruminantes. Informe Agropecuário, v.10, n.119, p.36-38, 1984.

CHEN, X.B.; GOMES, M.J. Estimation of microbial protein supply to sheep and cattle based on urinary excretion of purine derivatives- an overview of technical details. International feed research unit. Aberdeen Rowett Research Institute, 1992. $21 \mathrm{p}$. (Occasional publication).

COCHRAN, R.C.; ADAMS, D.C.; WALLACE, J.D. et. al. Predicting digestibility diets with internal markers: evaluation of four potential markers. Journal of Animal Science, v.63, p.1476$483,1986$.

GONDA, H.L.; LINDBERG, J.E. Effect of diet on milk allantoin and its relationship with urinary allantoin in dairy cows. Journal of Dairy Science, v.80, n.2, p.364-373, 1997.

HEAD, H.H.; GULAY, M.S. Recentes avanços na nutrição de vacas no período de transição. In: SINLEITE, 2., 2000, Lavras: Universidade Federal de Lavras, 2000. p.121-136.

JOHNSON, L.M.; HARRISONS, J.H.; RILEY, R.E. Estimation of the flow of microbial nitrogen to the duodenum using urinary uric acid or allantoin. Journal of Dairy Science, v.81, n.9, p.2408-2420, 1998.

JONKER, J.S.; KOHN, R.A.; ERDMAN, R.A. et al. Milk urea nitrogen target concentrations for lactating dairy cows fed according to national research council recommendations. Journal of Dairy Science, v.82, n.6, p.1261-1273, 1999.

JONKER, J.S.; KOHN, R.A.; ERDMAN, R.A. et al. Using milk urea nitrogen to predict nitrogen excretion and utilization efficiency in lactating dairy cows. Journal of Dairy Science, v.81, n.10, p.2681-2692, 1998.

KAUFFMAN, A.J.; ST-PIERRE, N.R. The relationship of milk urea nitrogen to urine nitrogen excretion in Holstein and Jersey cows. Journal of Dairy Science, v.84, n.10, p.2284-2294, 2001.

KONH, R.A.; KALSCHEUR, K.F.; RUSSEK-COHEN, E. Evaluation of models to estimate urinary nitrogen and expected milk urea nitrogen. Journal of Dairy Science, v.85, n.1, p.227-233, 2002 .
LARSON, S.F.; BUTLER, W.R.; CURRIE, W.B. Reduced fertility associated with lown progesterone postbreeding and increased milk urea nitrogen in lactating cows. Journal of Dairy Science, v.80, n.7, p.1288-1295, 1997.

LICITRA, G.; HERNANDEZ, T.M.; Van SOEST, P.J. Standardization of procedures for nitrogen fractionation of ruminant feeds. Animal Feed Science and Technology, v. 57, n.4, p.347-358, 1996

McCORMICK, M.E.; REDFEARN, D.D.; WARD, J.D. et al. Effect of protein source and soluble carbohydrate addition on rumen fermentation and lactation performance of Holstein cows. Journal of Dairy Science, v.84, n.7, p.1686-1697, 2001.

NATIONAL RESEARCH COUNCIL - NRC. Nutrient requirements of dairy cattle. 7.ed. Washington, D.C.: National Academy Press, 2001. 381p.

OLIVEIRA, A.S.; VALADARES, R.F.D.; VALADARES FILHO, S.C. et al. Produção de proteína microbiana e estimativas das excreções de derivados de purinas e de uréia em vacas lactantes alimentadas com rações isoprotéicas contendo diferentes níveis de compostos nitrogenados não-protéicos. Revista Brasileira de Zootecnia, v.30, n.5, p.1621-1629, 2001.

RAJALA-SCHULTZ, P.J.; SAVILLE, W.J.A.; FRAZER, G.S. et al. Association between milk urea nitrogen and fertility in Ohio dairy cows. Journal of Dairy Science, v.84, n.2, p.482-489, 2001.

RENNÓ, L.N.; VALADARES, R.F.D.; VALADARES FILHO, S.C. et al. Estimativa da produção de proteína microbiana pelos derivados de purinas na urina em novilhos. Revista Brasileira de Zootecnia, v.24, n.4, p.1223-1234, 2000.

SILVA, D.J.; QUEIROZ, A.C. Análise de alimentos: métodos químicos e biológicos. 3.ed. Viçosa, MG: Universidade Federal de Viçosa, 2002. 235p.

SILVA, R.M.N; VALADARES, R.F.D.; VALADARES FILHO, S.C. et al. Uréia para vacas em lactação. 2. Estimativa do volume urinário, da produção microbiana e da excreção de uréia. Revista Brasileira de Zootecnia, v.30, n.6, p.1948-1957, 2001.

SOUZA, A.L.; GARCIA, R.; BERNARDINO, F.S. et al. Casca de café em dietas de carneiros: consumo e digestibilidade. Revista Brasileira de Zootecnia, v.33, n.6, p.2170-2176, 2004 (supl. 2).

UNIVERSIDADE FEDERAL DE VIÇOSA - UFV. SAEG - Sistema de análises estatísticas e genéticas. Versão 7.1. Viçosa, MG: 1997. 150p. (Manual do usuário).

VALADARES, R.F.D.; BRODERICK, G.A.; VALADARES FILHO, S.C. et al. Effect of replacing alfalfa with high moisture corn on ruminal protein synthesis estimated from excretion of total purine derivatives. Journal of Dairy Science, v.82, n.12, p.2686-2696, 1999.

VERBIC, J.; CHEN, X.B.; MACLEOD, N.A. et al. Excretion of purine derivatives by ruminants. Effect of microbial nucleic acid infusion on purine derivative excretion by steers. Journal Agriculture Science, v.114, n.3, p.243-248, 1990. 